\title{
Formic acid poisoning with suicidal intent: a report of 53 cases
}

\author{
N. Rajan', R. Rahim² and S. Krishna Kumar ${ }^{3}$ \\ ${ }^{\prime}$ The Memorial Hospital, Darlington, Co. Durham, UK $;{ }^{2}$ Medical School Hospital, Trivandrum, Karala State, \\ South India and ${ }^{3}$ Medical College Hospital, Trivandrum, Karala State, South India.
}

\begin{abstract}
Summary: A report of 53 cases of formic acid ingestion with suicidal intention is presented. The patients were seen in one hospital in Kerala State over a 3 year period. Fifteen patients died and 38 patients survived. The pattern of clinical features seen is presented.
\end{abstract}

\section{Introduction}

Kerala State lies in the south western coastal region of the Indian sub-continent and has a total population of some twenty-five millions. The economy is predominantly agricultural. The labour is family-based and those engaged in rubber production collect the latex from the trees by tapping, harden it at once by admixture with formic acid and then bring it to the homestead for further processing prior to sale in sheet form.

The formic acid required for this purpose is readily available commercially, with the minimum of control of sale and supply and, in this way, it is easily accessible to all members of those families working with rubber, as well as to their friends and neighbours. Although suicide by hanging, drowning, ingestion of pesticides and different corrosives, is not uncommon in Kerala - despite this act being a crime in law formic acid seems to be the favoured agent for selfdestruction, especially among low income families and labourers. Characteristically pungent and corrosive, it is rarely swallowed accidentally (Malizia et al., 1977); it is occasionally exploited homicidally.

\section{Patients}

The University Hospital at Trivandrum draws acutely ill patients from an area within about a 20-30 mile radius. Victims of poisoning, like other emergencies, are normally treated in the first place at the primary Health Centres situated in the villages. Thence transfer can be arranged for the more serious casualties to the University Medical Centre. During the three years

N. Rajan, B.Sc., M.B., B.S., D.P.M.I.; R. Rahim, B.Sc., M.B., B.S.; S. Krishna Kumar, M.D., M.R.C.P.

Accepted: 10 May 1983
1980-82 inclusive, 53 cases of acute, formic acid poisoning were dealt with in this manner, 38 of whom survived and 15 died. The age range was 16 to $46 y$, mean $25 \mathrm{y}$ and there were 30 males.

\section{Clinical features}

Table I shows the number of patients suffering major complications. The majority of the lesions were evident in the gastro-intestinal tract, with facial (typically circumoral) burns and ulceration of the oral and pharyngeal mucosa. Abdominal pain was accompanied by haematemesis and dysphagia. Later complications included contractures and keloid formation on the affected area of the skin and, notably, oesophageal stricture, for which reparative surgery was needed.

The respiratory system was affected by inhalation pneumonitis with cough, dyspnoea, and cyanosis, which could proceed to respiratory infection and respiratory failure.

The changes in the cardiovascular system were nonspecific, both brady- and tachy-arrhythmias being observed, frequently accompanied by profound vascular hypotension.

More devastating were the changes in the renal system, haematuria usually appearing within a few hours of ingestion of the acid, this being succeeded by acute renal failure, sometimes of dramatically rapid onset, but in less severe cases after a day or so. In two cases of this kind subjected to renal biopsy, the histology indicated toxic, tubular necrosis.

The patients were hardly ever obtunded, being restless and agonized with pain, while consciousness was preserved, even in the ultimately fatal cases, almost to the point of death.

(C) The Fellowship of Postgraduate Medicine, 1985 
Table I Major complications in 53 cases of formic acid ingestion.

\begin{tabular}{lccccc}
\hline & Oesophageal stricture & Inhalation pneumonitis & Renal failure & Hypotension & Unconsciousness \\
\hline Male & 10 & 23 & 12 & 7 & 4 \\
Female & 6 & 22 & 8 & 10 & 5 \\
TOTAL & 16 & 45 & 20 & 17 & 9 \\
\hline
\end{tabular}

$10 \mathrm{ml}$ by mouth could prove lethal, death then taking place within hours, regardless of treatment. Those believed to have taken $15 \mathrm{ml}$ to a mouthful were likely to be found dead.

Among the 15 deaths, 6 succumbed to severe vascular hypotension and respiratory arrest, 4 died of acute renal failure and 5 failed to recover from gastrointestinal haemorrhage.

\section{Treatment}

No specific measures being applicable, treatment was essentially supportive. Antacids, milk and egg-white were cautiously administered orally, intravenous fluids and electrolytes were infused to counter 'shock', antibiotics were indicated prophylactically for infection, diuretics were given to promote renal function and hydrocortisone was prescribed systemically. Sedation was afforded by diazepam, pain relief generally demanded diamorphine, while that locally in the mouth was mollified by irrigations of lignocaine. Acute renal failure called for either peritoneal dialysis (Berlyne et al., 1964; Krishnakumar et al., 1975), or haemodialysis, while blood loss was corrected by transfusions.

Progress was monitored by the usual biochemical and haematological investigations, including bleeding and clotting times and subsequently, in some instances, barium swallow and renal biopsy were performed.

In Kerala State, suicide and attempted suicide are rated as crimes, so with the exception of the one accident, all these patients had to be reported to the Authorities. Because of their past history, 6 of these people were referred for psychiatric care.

\section{References}

BERLYNE, G.M., JONES, J.H., HEWITT, V. \& NILWARANGKUR, S. (1964). Protein loss in peritoneal dialysis. Lancet, i, 738.

HARVEY, D.R. (1968). Kettle descaler poisoning. Practitioner, 200, 180.

KRISHNA KUMAR, S., RAJAN, N. \& MATHEW ROY, V.C. (1975). Peritoneal dialysis in acute renal failure following viper bite. Kerala Medical Journal, XV, 1975.

\section{Discussion}

It would seem that, in Europe, acute formic acid $\vec{\theta}$ poisoning is unusual. Three examples arising accidentally and all accompanied by survival have been $\vec{\omega}$ described (Harvey, 1968) whereas another three cases of deliberate ingestion all ended fatally (Naik et al., 1980).

Since formic acid is so readily to hand in Kerala, especially within the farming community, it presents itself as a convenient and simple vehicle for self- $\overrightarrow{\dot{\omega}}$ poisoning in this country, as a sequel frequently to $w$ quite minor emotional upsets and in ignorance of the $\frac{\text { ? }}{2}$ dire consequences that may develop. Even when survival has been assured the complications such as oesophageal stricture and extensive scarring of the skin and mucosa demand expert correction by laryngologists and plastic surgeons.

As a preventive policy, more enlightenment of th population about the dangers of swallowing formit. acid and a stricter control over its sale and supply might be worthwhile.

\section{Acknowledgements}

We are thankful to Dr E.L. Sutherland, Director and Senior Consultant Psychiatrist; Dr G.P. Bray, Clinical Tutor; Dr J. Hampson, Senior Consultant Physician; The Memorial Hospital, South West Durham Area Health Authority; The Superintendent, Medical College Hospital, Trivandrum and The Principal, Medical College Hospital, Trivandrum, Kerala State, South India, for permitting us to collect the data and to publish this report.

MALIZIA, E., REALE, C., PEITROLPAOLI, P. \& DE TITIS, G.C. N (1977). Formic acid intoxications. Acta pharmacologica et toxicologica (Suppl.), 42, 342.

NAIK, R.B., STEPHENS, W.P., WILSON, D.J., WALKER, A. \& LEE, H.A. (1980). Ingestion of formic acid-containing agents - report of three fatal cases. Postgraduate Medical Journal, 56, 451. 